\title{
Prostaglandin and thromboxane production by the rat uterus and ovary in vitro during the oestrous cycle
}

\author{
N. L. Poyser and Fiona M. Scott \\ Department of Pharmacology, University of Edinburgh, l George Square, \\ Edinburgh EH8 9JZ, U.K.
}

\begin{abstract}
Summary. The major prostaglandin (PG) synthesized by homogenates of the rat uterus and ovary in vitro was prostacyclin (PGI-2), as reflected by the amounts of 6-oxo-PGF-1 $\alpha$ produced. Thromboxane production by both tissues was low, whereas appreciable quantities of PGF-2 $\alpha$, PGE-2 and PGD-2 were produced. Prostaglandin production by the uterus was higher on Day 1 (oestrus) than on Day 3 (dioestrus), although the ratio of the amounts of the PGs formed remained fairly constant for each day. There was no daily variation in the amounts of PGs synthesized by the ovary.

Metabolism of PGF- $2 \alpha$ by the rat uterus and ovaries was generally low, although the ovaries had a higher metabolizing capacity than the uterus. Metabolism by the uterus was higher on Day 1 than on Day 3 of the cycle. The decreased production of PG by the uterus on Day 3 is therefore not due to increased metabolism.
\end{abstract}

\section{Introduction}

The uterus and ovaries of the rat synthesize prostaglandin (PG) F-2 $\alpha$ and PGE-2 during the oestrous cycle (Saksena, Shaikh \& Shaikh, 1973; Ham, Cirillo, Zanetti \& Kuehl, 1975; LeMaire, Leidner \& Marsh, 1975; Armstrong \& Zamecnik, 1975; Bauminger \& Lindner, 1975). In guinea-pigs, there is an increase in this synthesizing capacity at the end of the oestrous cycle (Poyser, 1972; Sharma, Wilson \& Pugh, 1976). A similar increase occurs in uterine PGF-2 $\alpha$ production in the sheep (Alwachi, Bland \& Poyser, 1979). This study has therefore investigated whether daily variations occur in uterine and ovarian prostaglandin production during the rat oestrous cycle. As the prostaglandin synthetase complex of enzymes forms several products from arachidonic acid, the amounts of PGF-2 $\alpha$, PGE-2, PGD-2, 6-oxo-PGF-1 $\alpha$ (reflecting prostacyclin (PGI-2) production), and thromboxane (TX) B-2 (reflecting TXA-2 production) synthesized have been measured.

\section{Materials and Methods}

Wistar rats were housed under controlled lighting conditions (lights on 08:00-20:00 h). Vaginal smears were taken daily and examined microscopically. Day 1 (oestrus) of the cycle was taken as the day of maximum cornification preceding the day of leucocytic infiltration. All rats used had shown at least 2 regular 4-day cycles before being killed (10:00-12:00 h) on a particular day of the cycle. The rats were allocated to one of the following experiments.

Experiment 1 . The uterus and ovaries from each rat were removed, weighed, homogenized (in $15 \mathrm{ml}$ and $10 \mathrm{ml} \mathrm{Krebs'} \mathrm{solution} \mathrm{respectively)} \mathrm{and} \mathrm{incubated} \mathrm{for} 90 \mathrm{~min}$ at $37^{\circ} \mathrm{C}$, and the 
PGs were extracted by methods previously described (Mitchell, Poyser \& Wilson, 1977; Fenwick, Jones, Naylor, Poyser \& Wilson, 1977). The amounts of PGF-2 $\alpha$, PGE-2 and 6-oxo-PGF- $1 \alpha$ formed were measured by radioimmunoassay (RIA), while PGD-2 and TXB-2 were measured by gas chromatography-mass spectrometry.

Experiment 2. The uterus and ovaries of each rat were quickly removed, weighed and homogenized in $15 \mathrm{ml}$ absolute ethanol. Each homogenate was centrifuged at $1000 \mathrm{~g}$ for $15 \mathrm{~min}$ and the supernatant liquid withdrawn. The precipitate was washed with $5 \mathrm{ml}$ absolute ethanol, centrifuged at $1000 \mathrm{~g}$ for $15 \mathrm{~min}$ and the washings were combined with the original extract. Each extract was evaporated to dryness, under reduced pressure at $45^{\circ} \mathrm{C}$, dissolved in $10 \mathrm{ml}$ distilled water, and the PGs present were extracted and measured as in Exp. 1.

Experiment 3. The uterus and ovaries were removed from 4 rats on every day of the oestrous cycle. The two uterine horns were separated, and the ovaries from each rat were also kept separate. Each uterine horn and ovary was weighed and homogenized in 10 and $5 \mathrm{ml} \mathrm{Krebs'}$ solution respectively. Nicotinamide-adenine dinucleotide (NAD $+2 \mathrm{mM})$ and PGF- $2 \alpha(2 \mu \mathrm{g} / \mathrm{ml})$ were added to one uterine horn and one ovarian homogenate from each animal. A total of 0.5 $\mu \mathrm{Ci}\left[{ }^{3} \mathrm{H}\right]$ PGF- $2 \alpha$ (sp. act. $160 \mathrm{Ci} / \mathrm{mmol}$ : Radiochemical Centre, Amersham, U.K.) was added to all homogenates, which were then incubated. The PGs were extracted as in Exp. 2. The dried extracts were then dissolved in $0.15 \mathrm{ml}$ methanol and subjected to analysis by thin-layer chromatography by methods described previously (Maule Walker \& Poyser, 1978). The percentage metabolism of PGF-2 $\alpha$ was calculated as described for guinea-pig uterine and ovarian tissues (Poyser, 1979).

A reference plate onto which had been spotted $10 \mu \mathrm{g}$ PGF-2 $\alpha, 10 \mu \mathrm{g}$ 15-oxo-PGF-2 $\alpha$, and $10 \mu \mathrm{g}$ 13,14-dihydro-15-oxo-PGF-2 $\alpha$ was analysed and the $R_{\mathrm{F}}$ values of PGF-2 $\alpha$ and its main metabolites calculated.

\section{Assay procedures}

Efficiency of extraction. Lowering the acidity of aqueous solutions with $1 \mathrm{M}-\mathrm{HCl}$ to $\mathrm{pH}$ 4-4.5 followed by 3 extractions with 2 volumes of ethyl acetate is a well established method for efficiently extracting PGE-2 and PGF-2 $\alpha$. In the present experiment, this extraction procedure was re-examined to investigate whether PGD-2, TXB-2 and 6-oxo-PGF-1 $\alpha$ were also extracted efficiently. The appropriate tritiated PG or thromboxane $(0.5 \mu \mathrm{Ci})$ and $1-2 \mu \mathrm{g}$ of unlabelled PG $/ \mathrm{ml}$ were added to $10 \mathrm{ml}$ Krebs' solution and extracted as above. The percentage recoveries (mean \pm s.e.m., $n=3$ ) at $\mathrm{pH} 4.0$ were $94 \pm 3$ for PGF-2 $\alpha, 92 \pm 5$ for PGE-2, $91 \pm 2$ for PGD-2, $98 \pm 5$ for TXB-2 and $65 \pm 2$ for 6-oxo-PGF- $1 \alpha$. At pH $4.5,63.4 \pm 2.5 \%$ of the added $\left[{ }^{3} \mathrm{H}\right] 6$-oxo-PGF- $1 \alpha$ was recovered, but the percentage recovery fell to $35.9 \pm 4.7$ at $\mathrm{pH} 5.0$. Lowering the $\mathrm{pH}$, even down to $1 \cdot 5$, did not increase the percentage yield of $\left[{ }^{3} \mathrm{H}\right] 6$-oxo-PGF- $1 \alpha$. The reasons for this lower recovery are not known.

Radioimmunoassays. PGF-2 $\alpha$ was measured by an antibody raised in rabbits in this laboratory (Dighe, Emslie, Henderson, Rutherford \& Simon, 1975). The cross-reactivities are listed in Table 1. Although the antibody does not distinguish between PGF-2 $\alpha$ and PGF-1 $\alpha$, it was probable that only PGF-2 $\alpha$ was being measured since the rat uterus produces very little PGF-1 $\alpha$ (Fenwick et al., 1977). The detection limit of the assay was $25 \mathrm{pg}$, and the intra- and inter-assay coefficients of variation were 10.9 and $7.7 \%$ respectively. The quantity incorporated into each assay for calculating the inter-assay coefficient of variation was $160 \mathrm{pg}$. The intra-assay coefficient of variation was calculated from the duplicate results obtained for each biological sample assayed.

PGE-2 was measured using an antibody, raised in rabbits and purchased from the Pasteur Institute (Paris), which has previously been tested and found suitable for use in this laboratory (Mitchell et al., 1977). The cross-reactivities are listed in Table 1. Little PGE-1 is produced by the rat uterus (Fenwick et al., 1977), and it is probable that only PGE $_{\mathrm{S}} \mathbf{2}_{\mathrm{c}}$ was being measured 
Table 1. Results of cross-reactivity studies with antisera raised against prostaglandins

\begin{tabular}{lccc}
\hline & \multicolumn{3}{c}{ \% Cross-reaction } \\
\cline { 2 - 5 } \multicolumn{1}{c}{ Compound } & PGF-2 $\alpha$ & PGE-2 & 6-Oxo-PGF-1 $\alpha$ \\
\hline PGF-2 $\alpha$ & 100 & 0.17 & 5.8 \\
PGE-2 & 0.8 & 100 & 6.8 \\
PGD-2 & 3.4 & 0.008 & 0.073 \\
PGA-2 & 0.04 & 0.14 & 0.036 \\
PGB-2 & 0.14 & 0.05 & 0.031 \\
6-Oxo-PGF-1 $\alpha$ & 1.2 & 0.002 & 100 \\
TXB-2 & 0.07 & 0.07 & 0.003 \\
PGF-2 $\beta$ & 0.83 & - & - \\
PGF-1 $\alpha$ & 100 & - & 0.12 \\
PGE-1 & 0.65 & 6.6 & 2.0 \\
15-Oxo-PGF-2 $\alpha$ & 2.8 & - & - \\
15-Oxo-PGE-2 & - & 0.58 & - \\
13,14-Dihydro-15-oxo-PGF-2 $\alpha$ & 0.67 & - & 0.105 \\
13,14-Dihydro-15-oxo-PGE-2 & - & 0.056 & 0.018 \\
\hline
\end{tabular}

Table 2. Concentrations (mean \pm s.e.m. for 5 observations) of prostaglandins in rat ovary and uterus during the oestrous cycle

\begin{tabular}{|c|c|c|c|c|}
\hline \multirow{2}{*}{$\begin{array}{c}\text { PG conc. } \\
\text { (ng/100 mg tissue) }\end{array}$} & \multicolumn{4}{|c|}{ Day of cycle } \\
\hline & Day 1 & Day 2 & Day 3 & Day 4 \\
\hline \multicolumn{5}{|l|}{ Uterus } \\
\hline 6-Oxo-PGF-1a & $3.8 \pm 0.8$ & $3.6 \pm 0.7$ & $2.4 \pm 0.2$ & $1.5 \pm 0.4^{*} \dagger$ \\
\hline PGF- $2 \alpha$ & $1.9 \pm 0.3$ & $1.2 \pm 0.3$ & $1 \cdot 2 \pm 0 \cdot 1$ & $1.6 \pm 0.2$ \\
\hline PGE-2 & $0.32 \pm 0 \cdot 1$ & $0.25 \pm 0.04$ & $0.29 \pm 0.03$ & $0.18 \pm 0.02$ \\
\hline \multicolumn{5}{|l|}{ Ovary } \\
\hline 6-Oxo-PGF-1a & $5 \cdot 8 \pm 1 \cdot 1$ & $4 \cdot 4 \pm 1 \cdot 3$ & $2.7 \pm 0.7^{*}$ & $3.1 \pm 0.8$ \\
\hline PGF-2 $\alpha$ & $2.1 \pm 0.2$ & $1 \cdot 3 \pm 0 \cdot 3^{*}$ & $0.82 \pm 0.07^{*}$ & $1 \cdot 2 \pm 0 \cdot 2^{*}$ \\
\hline PGE-2 & $3.9 \pm 1.5$ & $0.92 \pm 0.46$ & $0.29 \pm 0.03^{*}$ & $0.26 \pm 0.03^{*}$ \\
\hline
\end{tabular}

* Significantly lower than on Day $1(P<0.05)$.

+ Significantly lower than on Day $2(P<0.05)$.

The detection limit was $4 \mathrm{pg}$, and the intra- and inter-assay coefficients of variation were 10.4 and $12 \cdot 1 \%$, respectively. The quantity used for calculating the inter-assay coefficient was $20 \mathrm{pg}$ and the intra-assay coefficient was calculated as for PGF- $2 \alpha$.

An antibody raised and tested in our laboratory (Dighe, Jones \& Poyser, 1978) was used to measure 6-oxo-PGF-1 $\alpha$. The immunized rabbits have now produced an antiserum which binds $57 \%$ of $\left.30 \mathrm{pg} \mathrm{[}{ }^{3} \mathrm{H}\right] 6-\mathrm{oxo}-\mathrm{PGF}-1 \alpha$ (sp. act. $90-105 \mathrm{Ci} / \mathrm{mmol}$ ) at a dilution of 1 in 13000 . The cross-reactivities of this antiserum are listed in Table 1 . The accuracy of the assay was assessed by adding known amounts $(200,500$ and $1000 \mathrm{ng})$ of 6-oxo-PGF-1 $\alpha$ to $20 \mathrm{ml}$ Krebs' solution, lowering the $\mathrm{pH}$ of the solution to 3.5 or 4 with $1 \mathrm{M}-\mathrm{HCl}$, extracting the PG by methods described previously, and then measuring the amounts of 6-oxo-PGF-1 $\alpha$ recovered. The values obtained were corrected for a mean recovery of $65 \%$ and were respectively (mean \pm s.e.m.. $n=3) 191 \pm 23,521 \pm 26$ and $973 \pm 35 \mathrm{ng}$ at pH 3.5 and $229 \pm 13,496 \pm 28$ and $976 \pm 38 \mathrm{ng}$ at $\mathrm{pH}$ 4. In addition, a standard solution of $640 \mathrm{pg} 6-\mathrm{oxo}-\mathrm{PGF}-1 \mathrm{\alpha} / \mathrm{ml}$ assayed in 8 consecutive assays gave a value of $638 \pm 31$ (s.e.m.) $\mathrm{pg} / \mathrm{ml}$, with an inter-assay coefficient of variation of $13.5 \%$. The intra-assay coefficient of variation was $12.4 \%$, and the detection limit was $25 \mathrm{pg}$. It

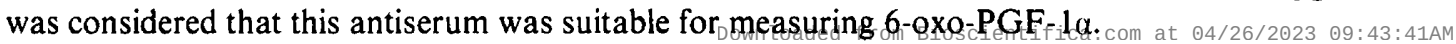


Measurement by gas chromatography-mass spectrometry. Assays were carried out on a VG Micromass $7070 \mathrm{~F}$ double-focussing gas chromatogram-mass spectrometer, using the multiple ion detector unit. The column was packed with $3 \%$ OV1 on Supelcoport (Supelco Inc., Belleforte, U.S.A.), the helium gas flow was $30 \mathrm{ml} / \mathrm{min}$, and the column temperature was $265^{\circ} \mathrm{C}$. The preparation of $\mathrm{PG}$ and TX derivatives for measurement was as described by Fenwick et al. (1977) and Poyser (1977). PGD-2 was monitored by recording the ion at $\mathrm{m} / \mathrm{e} 510$ of the methyl ester-butyloxime-trimethylsilyl ether derivative (Me/BuO-TMS; carbon value of 2nd isomer $=26 \cdot 1$ ). The corresponding ethyl ester derivative of PGD-2 (Et-BuO-TMS; carbon value of 2 nd isomer $=26.4$ ) was used as the internal standard, and the corresponding ion at $\mathrm{m} / \mathrm{e} 524$ was recorded. Standard quantities of 5, 10, 20 and $40 \mathrm{ng}$ PGD-2 (as the Me-BuO-TMS derivative) together with $40 \mathrm{ng}$ PGD-2 (as the Et-BuO-TMS derivative) were injected into the apparatus, and the heights of the ions produced at m/e 510 and m/e 524 were recorded. A standard curve (which is in fact a straight line) was obtained by plotting the ratio of the heights of the 510 and 524 ions against the standard quantity of PGD-2. TXB-2 was recorded in a manner similar to that for PGD-2 using the Me-BuO-TMS derivative (carbon value = 26.9), with the EtBuO-TMS derivative (carbon value $=27.2$ ) as the internal standard. Both derivatives produce the same ion at $\mathrm{m} / \mathrm{e}$ 301. A standard curve was constructed using $1,2 \cdot 5,5$ and $10 \mathrm{ng}$ TXB-2 (Me-BuO-TMS derivative), with $10 \mathrm{ng}$ TXB-2 (Et-BuO-TMS derivative) being used as the internal standard. The lowest quantity of standard used represents the detection limit for each assay.

Each uterine and ovarian extract was stored in $10 \mathrm{ml}$ ethyl acetate at $-20^{\circ} \mathrm{C}$. For assay, half of each sample $(5 \mathrm{ml})$ was added to an Eppendorf tube and evaporated to dryness. The methyl ester was formed, followed by the addition of $120 \mathrm{ng}$ PGD-2 and $30 \mathrm{ng}$ TXB-2 as the ethyl esters. The butyloximes and trimethylsilyl ethers were then prepared. It proved impossible to monitor the ions at $\mathrm{m} / \mathrm{e} 301,510$, and 524 at the same time. This therefore necessitated assaying the samples separately for PGD-2 and TXB-2, one-third of each sample being injected into the gas chromatogram-mass spectrometer for each assay. The ratios of the heights of the appropriate ions were recorded and the amounts of PGD-2 and TXB-2 in each sample calculated.

\section{Statistical tests}

The results, expressed as mean \pm s.e.m., were analysed by Student's $t$ test.

\section{Results}

\section{Experiment 1}

Uterus. Small quantities of TXB-2 (3-5 ng/100 mg tissue) were detected in a few uterine samples but no other values could be obtained. Production of each of the 4 PGs by the uterus was significantly higher $(P<0.01)$ on Day 1 than on Day 3 of the cycle (Text-fig. $1 \mathrm{a})$. The ratio of the amounts of 6-oxo-PGF-1 $\alpha$, PGF, PGD-2 and PGE produced remained fairly constant at approximately $12: 3: 2: 1$ for each of the 4 days.

Ovary. There were no significant differences in the amounts of each PG and TXB-2 produced on the different days of the cycle (Text-fig. 1b). However, 6-oxo-PGF-1 $\alpha$ production did appear to increase at the expense of PGF production on Day 4. The total quantity of prostaglandins and thromboxanes produced on each day was remarkably constant (mean 396.5 $\mathrm{ng} / 100 \mathrm{mg}$ tissue; range $389 \cdot 7-403.4 \mathrm{ng} / 100 \mathrm{mg}$ tissue).

\section{Experiment 2}

The amounts of PGD-2 and TXB-2 in the uterus and ovary were too low for measurement by gas chromatography-mass spectrometry. In the outerus, mthere iwas ino daily ${ }_{0}$ variation $\odot \mathrm{in} 3: 41 \mathrm{AM}$ PGF- $2 \alpha$ or PGE-2 levels but those of 6 -oxo-PGF- $1 \alpha$ were significantly higher $\left(P<0^{*} \theta 5\right)^{\text {ron }}{ }^{\text {access }}$ 


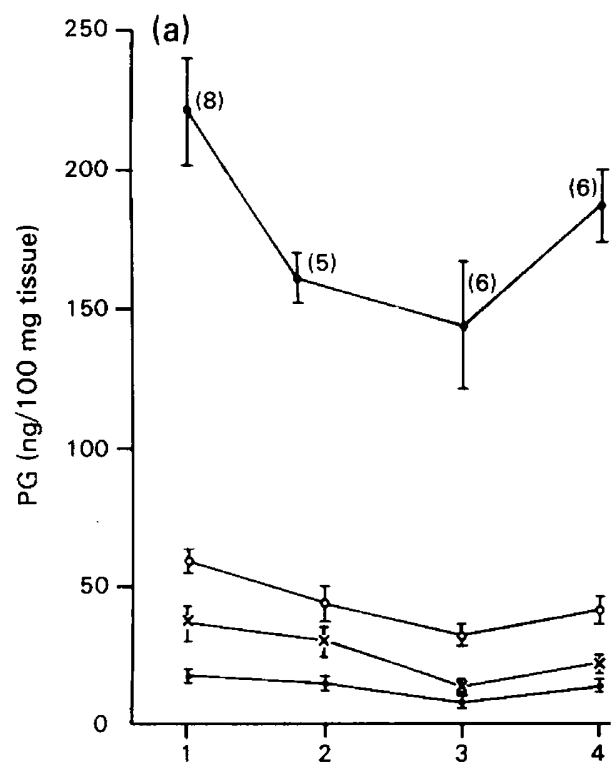

- 6-Oxo-PGF-1a

- PGF

$\times$ PGD-2

$\triangle \mathrm{PGE}$

TXB-2

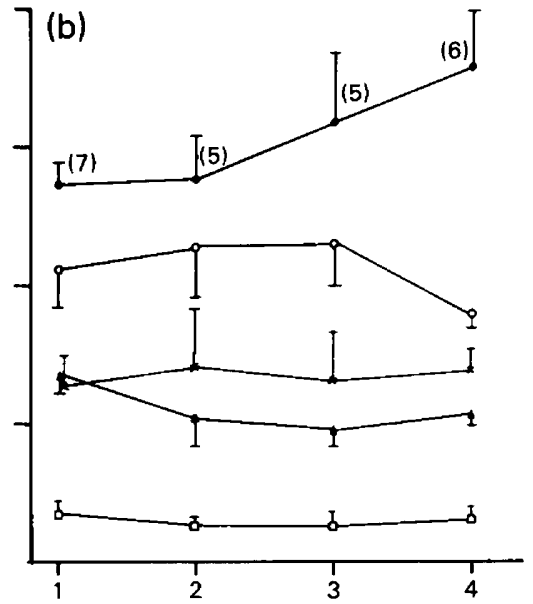

Days

Text-fig. 1. Prostaglandin production (mean \pm s.e.m.) by homogenates of (a) rat uterus and (b) rat ovary between 10:00 and 12:00 $\mathrm{h}$ on each day of the oestrous cycle. The numbers in parentheses indicate the numbers of rats used.

Table 3. Percentage metabolism (mean \pm s.e.m. for 4 observations) by rat uterine and ovarian homogenates of PGF-2 $\alpha$ into 15-oxo-PGF-2 $\alpha$ and 13,14-dihydro-15-oxo-PGF-2 $\alpha$ (Metabolites A), and an unknown Metabolite B (ovary only)

\begin{tabular}{|c|c|c|c|c|}
\hline \multirow[b]{2}{*}{$\%$ Metabolism } & \multicolumn{4}{|c|}{ Day of cycle } \\
\hline & Day 1 & Day 2 & Day 3 & Day 4 \\
\hline \multicolumn{5}{|l|}{ Uterus with NAD ${ }^{+}$} \\
\hline \multicolumn{5}{|l|}{ Metabolites A } \\
\hline $\begin{array}{l}\text { Total } \\
\text { per } 100 \mathrm{mg} \text { tissue }\end{array}$ & $\begin{array}{r}12 \cdot 1 \pm 0.8 \\
5 \cdot 1 \pm 0.6\end{array}$ & $\begin{array}{l}5.9 \pm 1.4^{*} \\
3.2 \pm 0.6 \dagger\end{array}$ & $\begin{array}{l}7.8 \pm 0.3^{*} \\
3.6 \pm 0.2 \dagger\end{array}$ & $\begin{array}{r}15.9 \pm 1.6 \\
5.3 \pm 0.7\end{array}$ \\
\hline \multicolumn{5}{|l|}{ Uterus without $\mathrm{NAD}^{+}$} \\
\hline \multicolumn{5}{|l|}{ Metabolites A } \\
\hline Total & $5.7 \pm 0.5$ & $4.6 \pm 0.5$ & $5.9 \pm 0.5$ & $5 \cdot 2 \pm 1 \cdot 0$ \\
\hline per $100 \mathrm{mg}$ tissue & $2.7 \pm 0.4$ & $2.6 \pm 0.6$ & $2.8 \pm 0.3$ & $1.9 \pm 0.5$ \\
\hline \multicolumn{5}{|l|}{ Ovary with $\mathrm{NAD}^{+}$} \\
\hline \multicolumn{5}{|l|}{ Metabolites A } \\
\hline Total & $31.4 \pm 2.6$ & $25 \cdot 3 \pm 0.7$ & $28.4 \pm 1.2$ & $34.4 \pm 4 \cdot 1$ \\
\hline per mg tissue & $0.61 \pm 0.02$ & $0.49 \pm 0.02 \ddagger$ & $0.44 \pm 0.04 \ddagger$ & $0.11 \pm 0.02$ \\
\hline \multicolumn{5}{|l|}{ Metabolite B } \\
\hline Total & $6.7 \pm 1.8$ & $5 \cdot 7 \pm 1.0$ & $7 \cdot 3 \pm 1 \cdot 2$ & $6.6 \pm 0.7$ \\
\hline per mg tissue & $0.12 \pm 0.03$ & $0.11 \pm 0.02$ & $0.11 \pm 0.02$ & $0.12 \pm 0.01$ \\
\hline \multicolumn{5}{|l|}{ Ovary without $\mathrm{NAD}^{+}$} \\
\hline \multicolumn{5}{|l|}{ Metabolites A } \\
\hline Total & $10.4 \pm 0.9$ & $6.7 \pm 0.7$ & $6 \cdot 6 \pm 1 \cdot 1$ & $8.3 \pm 1.5$ \\
\hline per $\mathrm{mg}$ tissue & $0.18 \pm 0.02$ & $0.12 \pm 0.01$ & $0.13 \pm 0.03$ & $0.19 \pm 0.03$ \\
\hline \multicolumn{5}{|l|}{ Metabolite B } \\
\hline Total & $1.7 \pm 0.5$ & $1.8 \pm 0.4$ & $1 \cdot 1 \pm 0.2$ & $1.4 \pm 0.3$ \\
\hline per mg tissue & $0.03 \pm 0.01$ & $0.04 \pm 0.01$ & $0.02 \pm 0.01$ & $0.03 \pm 0.01$ \\
\hline
\end{tabular}


Days 1 and 2 than on Day 4 (Table 2). In the ovary, the levels of all 3 prostaglandins measured were significantly higher $(P<0.05)$ on Day 1 than on Day 3 and, with the exception of 6-oxo-PGF-1 $\alpha$, than on Day 4 also.

\section{Experiment 3}

The uterus and ovaries both metabolized PGF-2 $\alpha \quad\left(R_{\mathrm{F}}=0.35\right)$ into a mixture of 15-oxo-PGF- $2 \alpha\left(R_{\mathrm{F}}=0.54\right)$ and 13,14-dihydro-15-oxo-PGF-2 $\alpha\left(R_{\mathrm{F}}=0.59\right)$. Due to the close proximity of these two metabolites on the thin-layer chromatographic plate, they were not separated for counting purposes, and the percentage metabolism of PGF-2 $\alpha$ into these two products is expressed as a single figure (Table 3). Metabolism of PGF-2 $\alpha$ in the absence of $\mathrm{NAD}^{+}$was low and there were no significant daily variations. The addition of $\mathrm{NAD}^{+}$increased PGF-2 $\alpha$ metabolism, the effect being greater for the ovaries than for the uterus. The production of the two major metabolites of PGF- $2 \alpha$ by the uterus was significantly higher on Days 1 and 4 of the cycle than on Days 2 and 3, both on a total $(P<0.01)$ and a unit $(P<0.05)$ weight basis. The production of similar metabolites by the ovary was significantly higher $(P<0.05)$ on Days 1 and 4 than on Days 2 and 3, but only when expressed on a unit weight basis. The ovary also metabolized PGF-2 $\alpha$ into a much less polar product $\left(R_{\mathrm{F}}=0.72\right)$ which was not identified. Its production was $\mathrm{NAD}^{+}$-dependent and showed no significant daily variation.

\section{Discussion}

The levels of prostaglandins in the rat uterus and ovaries are low. As the metabolism of prostaglandins by these organs, in the absence of $\mathrm{NAD}^{+}$, is also very low, the amounts of prostaglandins produced by homogenates of the rat uterus and ovary incubated in vitro reflect prostaglandin synthesis. The major prostaglandin synthesized by the uterus and ovaries was PGI-2 (as determined by measuring 6-oxo-PGF-1 $\alpha$ ) with lesser quantities (in descending order) of PGF-2 $\alpha$, PGD-2, PGE-2 and thromboxane. Studies with the pregnant rat uterus have indicated that the endometrium is the major site for PGF- $2 \alpha$ synthesis while the myometrium synthesizes predominantly PGI-2 (Williams, Sneddon \& Harney, 1974; Williams, Dembinskakiec, Zmuda \& Gryglewski, 1978). Both these tissues synthesize PGE-2, while the decidualized endometrium has been found to produce PGD-2 (Downing \& Williams, 1977). The site of production of the individual prostaglandins in the non-pregnant rat uterus merits further study.

In the present study uterine prostaglandin production was higher on Day 1 (oestrus) than on Day 3 (dioestrus), a finding which essentially agrees with the observations of Ham et al. (1975). However, in the latter study, PGF synthesis increased at the expense of PGE synthesis and during dioestrus PGE synthesis was actually 3 times higher than PGF synthesis. Our findings do not support these previous observations since PGF production always exceeded PGE production 3-fold, and the synthesis of any one prostaglandin did not occur at the expense of any other. The reason for this discrepancy may lie within the design of the experiments. We used homogenates of uterine tissue, utilized endogenous arachidonic acid liberated from bound stores during the homogenization procedure, and did not add any co-factors. Ham et al. (1975) used a microsomal uterine preparation, exogenous arachidonic acid. and the co-factors hydroquinone and reduced glutathione which promote PGE synthesis.

PGF levels in rat uterine venous plasma have been reported to be higher during dioestrus than oestrus (Saksena et al., 1973). These changes in plasma levels do not correlate with changes in the prostaglandin synthesizing capacity of the uterus. This is in contrast to the guinea-pig and sheep in which maximum uterine PGF-2 $\alpha$ synthesizing ability and output occur at the same time (Poyser, 1972; Blatchley, Donovan. Horton \& Poyser. 1972: Thorburn. Cox. Currie. Restall \& Schneider, 1973; Alwachi et al., 1979). In view of the present findingstitid ould be 4 relexant $\operatorname{tac} 43: 41 \mathrm{Am}$ 
investigate uterine venous plasma levels of all the prostaglandins during the rat oestrous cycle. The physiological significance of uterine prostaglandin production by the rat uterus during the cycle is not known, although it is probable that the changes in prostaglandin synthetase levels in the uterus can be correlated with oestradiol output from the ovary, as in the guinea-pig (Poyser 1976). Oestradiol does increase prostaglandin production by and output from the rat uterus (Ham et al., 1975; Castracane \& Jordan, 1975), and the increase in uterine prostaglandin-synthesizing capacity on Day 1 of the cycle may be due to the ovulatory surge of oestradiol which occurs on the previous day.

There were no daily changes in prostaglandin production by the ovary, and PGF- $2 \alpha$ production always exceeded PGE-2 production. However, prostaglandin synthesis by the rat ovary does rise and fall between the mornings of Day 4 (pro-oestrus) and Day 1 (oestrus), and the ratio of PGF to PGE production becomes reversed during this peak period (LeMaire et al., 1975; Bauminger \& Lindner, 1975). This increase in ovarian prostaglandin production is necessary for ovulation. Our study has shown that PGI-2 is the major prostaglandin produced by homogenates of rat ovary and it will be relevant to study the production of this compound by the rat ovary in the immediate pre- and post-ovulatory periods.

PGI-2 is the major product formed by homogenates of human ovarian follicles plus stromal cells, together with much smaller quantities of PGE-2 and PGF-2 $\alpha$ (Liedtke \& Seifert, 1978). The human corpus luteum synthesizes PGE-2 as the major product with smaller quantities of PGI-2 and PGF-2 $\alpha$. PGD-2 and thromboxane production were not studied. Different tissues within the ovary apparently have differing capacities for synthesizing the various prostaglandins. However, the cow and horse corpus luteum convert PGH-2 into predominantly PGI-2 (Sun, Chapman \& McGuire, 1977), so there may be species differences. The uterus and ovaries, due to their high PGI-2 synthesizing capacity, possibly secrete PGI-2 into the blood stream. PGI-2 so released may act as a circulating hormone, and aid in preventing platelet aggregation with PGI-2 produced by blood vessels. However, venous-arterial differences for PGI-2 across the uterus and ovaries need to be demonstrated to confirm this hypothesis.

This study was supported by the M.R.C. Prostaglandins and thromboxanes were kindly supplied by the Upjohn Company, U.S.A. 6-Oxo-PGF-1 $\alpha$ was kindly supplied by I.C.I., U.K., for the raising of antiserum. Data regarding the recoveries for PGD-2 and TXB-2 were supplied by Miss Christine A. Phillips. The gas chromatogram-mass spectrometer was purchased on a grant from the Wellcome Trust. The technical assistance of Miss Agnes Pelanis, Miss Lynne Gilchrist, Miss Sylvia North and Miss Fiona Howson is appreciated.

\section{References}

Alwachi, S.N., Bland, K.P. \& Poyser, N.L. (1979) Uterine prostaglandin F-2 $\alpha$ and E-2 production and content during the second half of the oestrous cycle of the sheep. Possible local control of the uterus by the ovary. Prostaglandins and Medicine 3, 23-32.

Armstrong, D.T. \& Zamecnik, J. (1975) Pre-ovulation elevation of rat ovarian prostaglandin $F$ and its blockade by indomethacin. Mol. cell. Endocr. 2, 125-131.

Bauminger, S. \& Lindner, H.R. (1975) Periovulatory changes in ovarian prostaglandin formation and their hormonal control in the rat. Prostaglandins 9, 737-751.

Blatchley, F.R., Donovan, B.T., Horton, E.W. \& Poyser, N.L. (1972) The release of prostaglandins and progesterone into the utero-ovarian venous blood of guinea-pigs during the oestrous cycle and following oestrogen treatment. J. Physiol., Lond. 228, 69-88.

Castracane, D.V. \& Jordan, V.C. (1975) Effect of estrogen and progesterone on uterine prostaglandin biosynthesis in the ovariectomised rat. Biol. Reprod. 13, 587-596.

Dighe, K.K., Emslie, H.A., Henderson, L.K., Rutherford, F. \& Simon, L. (1975) The development of antisera to prostaglandins B-2 and F-2 $\alpha$ and their analysis using solid-phase and double antibody radioimmunoassay methods. Br. J. Pharmac. 55, 503-514.

Dighe, K.K., Jones, R.L. \& Poyser, N.L. (1978) Development of a radioimmunoassay for measuring 6-oxo-prostaglandin F-1 a. Br. J. Pharmac. 63, Down406P.d from Bioscientifica.com at 04/26/2023 09:43:41AM 
Downing, I. \& Williams, K.I. (1977) Differential prostaglandin production by microsomal fractions of rat pregnant uterus. Br. J. Pharmac. 61, 158 P.

Fenwick, L., Jones, R.L., Naylor, B., Poyser, N.L. \& Wilson, N.H. (1977) Production of prostaglandins by the pseudopregnant rat uterus, in vitro, and the effect of tamoxifen, with the identification of 6keto-prostaglandin $\mathrm{F}-\mathrm{I} \alpha$ as a major product. $\mathrm{Br} . \mathrm{J}$. Pharmac. 59, 191-199.

Ham, E.E., Cirillo, V.J., Zanetti, M.E. \& Kuehl, F.A., Jr (1975) Estrogen-directed synthesis of specific prostaglandins in uterus. Proc. natn. Acad. Sci. U.S.A. 72, 1420-1424.

LeMaire, W.J., Leidner, R. \& Marsh, J.M. (1975) Pre and post ovulatory changes in the concentration of prostaglandins in rat graafian follicles. Prostaglandins 9, 222-229.

Liedkte, M.P. \& Seifert, B. (1978) Biosynthesis of prostaglandins in human ovarian tissue. Prostaglandins 16, 825-834.

Maule Walker, F.M. \& Poyser, N.L. (1978) The metabolism of prostaglandins by the guinea-pig uterus with particular reference to corpus luteal maintenance in early pregnancy. Br.J. Pharmac. 62 , 177-183.

Mitchell, S., Poyser, N.L. \& Wilson, N.H. (1977) Effect of p-bromophenacyl bromide, an inhibitor of phospholipase A-2, on arachidonic acid release and prostaglandin synthesis by the guinea-pig uterus in vitro. Br.J. Pharmac. 59, 107-113.

Poyser, N.L. (1972) Production of prostaglandins by the guinea-pig uterus. J. Endocr. 54, 147-159.

Poyser, N.L. (1976) Prostaglandin F-2 $\alpha$ is the uterine luteolytic hormone in the guinea-pig: the evidence reviewed. Adv. Prostaglandin Thromboxane Res. 2, 633-643.

Poyser, N.L. (1977) Identification of thromboxane B-2 in guinea-pig uterine homogenates. Experientia 33, 1561-1562.

Poyser, N.L. (1979) Effect of actinomycin D on uterine prostaglandin production and oestrous cycle length in guinea-pigs. J. Reprod. Fert. 56, 559-565.

Saksena, S.K., Shaikh, S.A. \& Shaikh, A.A. (1973) Uterine and peripheral plasma F-prostaglandins correlated with peripheral progesterone in cyclic rats. Prostaglandins 4, 243-249.

Sharma, S.C., Wilson, C.M.W. \& Pugh, D.M. (1976) In vitro production of prostaglandins $E$ and $F$ by the guinea-pig ovarian tissue. Prostaglandins 11, 555568.

Sun, F.F., Chapman, J.P. \& McGuire, J.C. (1977) Metabolism of prostaglandin endoperoxide in animal tissues. Prostaglàndins 14, 1055-1074.

Thorburn, G.D., Cox, R.I., Currie, W.B., Restall, B.J. \& Schneider, W. (1973) Prostaglandin F and progesterone concentrations in the utero-ovarian venous plasma of the ewe during the oestrous cycle and early pregnancy. J. Reprod. Fert., Suppl. 18, 151-158.

Williams, K.I., Sneddon, J.M. \& Harney, P.J. (1974) Prostaglandin production by the pregnant rat uterus in vitro and its relevance to parturition. Pol. J. Pharmac. Pharm. 26, 207-215.

Williams, K.I., Dembinska-kiec, A., Zmuda, A. \& Gryglewski, R.J. (1978) Prostacyclin formation by myometrial and decidual fractions of pregnant rat uterus. Prostaglandins 15, 343-350.

Received 31 October 1979 